\title{
Heart rate responses during the 6-minute walk test in pulmonary arterial hypertension
}

\author{
S. Provencher*, D. Chemla\# ${ }^{\#}$ P. Hervé
}

ABSTRACT: Patients with pulmonary arterial hypertension (PAH) exhibit a limited increase in stroke volume on exercise, and the heart rate (HR) increases may reflect the main mechanism that allows cardiac output to increase. The current prospective study documented the contribution of HR to the 6-min walking distance (6MWD) in idiopathic (IPAH) and nonidiopathic PAH.

Eighty-three patients (46 IPAH and 37 nonidiopathic PAH) underwent haemodynamic evaluation and a 6MWD test. Chronotropic response (peak walking HR minus resting HR) and peripheral oxygen saturation were monitored. Fifty-seven patients were also assessed after $5 \pm 2$ months of treatment (bosentan $n=38$, epoprostenol $n=14$, bosentan-epoprostenol $n=3$, iloprost $n=2$ ).

Before treatment, the 6MWD was related to numerous demographic, haemodynamic and walking test characteristics. Stepwise regression analysis indicated that the only factors significantly associated with the 6MWD were stroke volume and chronotropic response in both IPAH and nonidiopathic PAH patients. Following treatment, changes in 6MWD were significantly related to changes in chronotropic response in both IPAH and nonidiopathic PAH.

In conclusion, baseline stroke volume and chronotropic response were independently associated with the 6-min walking distance in pulmonary arterial hypertension. The lack of chronotropic response may reflect the loss in normal physiological reserve in more unwell patients.

KEYWORDS: Exercise test, heart rate, pulmonary hypertension, stroke volume

I $\mathrm{n}$ patients with pulmonary arterial hypertension (PAH), evidence-based clinical practice guidelines recommend serial determinations of exercise capacity assessed by the 6-min walk test (6MWT) [1-4]. Indeed, the 6MWT provides benchmarks for disease severity, response to therapy, and progression [1-5]. This submaximal exercise test is simple, safe, reproducible, inexpensive and representative of daily-life activities [6]. The 6MWT is now part of routine evaluation in most pulmonary hypertension clinics in order to guide physicians in their decision making. It has recently been suggested that the 6MWT evaluation of PAH patients could be improved by taking into account the level of arterial desaturation during exercise [7], whereas the potential contribution of other responses during exercise remains to be documented [8].

The aim of the present study was to document heart rate (HR) responses during the 6MWT in patients with PAH. The rationale was as follows. Exercising $\mathrm{PAH}$ patients exhibit a limited increase in stroke volume [9-11], such that the increase in cardiac output is mainly achieved through increases in HR. The HR increases could have opposite pathophysiological meanings
[12-15]. Disproportionate HR increase may reflect the severity of the disease. Alternatively, it may reflect beneficial chronotropic capabilities in reserve, thus allowing the cardiac output to increase. In the present study, the hypothesis that differences in walking capacities were associated with differences in $\mathrm{HR}$ responses in $\mathrm{PAH}$ patients was tested.

\section{METHODS}

\section{Study population}

From November 2003 to September 2004, patients referred to the current authors' institution (Hôpital Antoine Béclère, Clamart, France) for the evaluation of PAH were prospectively evaluated $(n=83)$. PAH was defined as a mean pulmonary arterial pressure $>25 \mathrm{mmHg}$ at rest or $>30 \mathrm{mmHg}$ during exercise, with a pulmonary artery occlusion pressure $<15 \mathrm{mmHg}$ [16]. The final diagnosis was as follows: idiopathic PAH (IPAH; $n=46)$ and nonidiopathic PAH $(n=37)$, including PAH related to HIV $(n=11)$, connective tissue disease $(n=12)$ and portal hypertension $(n=14)$. Congenital heart disease was excluded from the study [17]. The current authors also excluded patients with baseline arterial oxygen saturation measured by pulse
AFFILIATIONS

*Centre des maladies vasculaires pulmonaires (UPRES EA 2705), Service de pneumologie et réanimation respiratoire, AP-HPUniversité Paris Sud XI, Hôpital Antoine Béclère, Clamart,

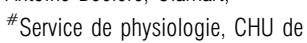
Bicêtre, Le Kremlin-Bicêtre, and "Centre chirurgical Marie-

Lannelongue, Le Plessis-Robinson, France.

CORRESPONDENCE

$S$. Provencher

Hôpital Antoine Béclère

157 rue de la Porte de Trivaux

92140 Clamart

France

Fax: 33146303824

E-mail:

steeveprovencher@hotmail.com

Received:

April 112005

Accepted after revision:

September 212005

SUPPORT STATEMENT

$S$. Provencher was the recipient of a fellowship grant from Université Laval, Québec, Canada.

European Respiratory Journal Print ISSN 0903-1936 Online ISSN 1399-3003 
oximetry $\left(\mathrm{SP}, \mathrm{O}_{2}\right)<85 \%$ on air or patients with continuous or ambulatory supplemental oxygen, a forced expiratory volume in one second or forced vital capacity $<70 \%$ of predicted, haemoglobin level $<110 \mathrm{~g} \cdot \mathrm{L}^{-1}$, body mass index $>35 \mathrm{~kg} \cdot \mathrm{m}^{-2}$ and those with musculoskeletal abnormality. At baseline, patients were not taking the following medication: prostacyclin derivatives; endothelin receptor antagonists; phosphodiesterase type- 5 inhibitors; calcium channel blockers; digoxin; or beta-blockers. Functional class was evaluated by a clinician unaware of the results of the 6MWT and haemodynamics, using the modified New York Heart Association (NYHA) functional classes [18]. Informed consent was obtained for all patients. The study was approved by the ethics board of the current authors' institution.

\section{MWT and haemodynamic evaluation}

The 6MWT was coached by the same physician (S. Provencher), according to the American Thoracic Society recommendations [6]. All patients had a practice test. A second test, performed $24 \mathrm{~h}$ later, was used for analysis. Ambulatory oxygen supplementation was not permitted during the test. Before the test, patients rested in a chair, located near the starting position, for $\geqslant 10 \mathrm{~min}$. $\mathrm{HR}$ and $\mathrm{SP}, \mathrm{O}_{2}$ were measured for $1 \mathrm{~min}$ at baseline, continuously during the test, and during the first minute of recovery by a pulse oxymeter (Nonin 2500; Nonin Medical, Plymouth, MN, USA) using finger or ear. Data were recorded every $4 \mathrm{~s}$ and were transferred on a personal computer. Resting $S \mathrm{P}, \mathrm{O}_{2}$, minimal $\mathrm{SP}, \mathrm{O}_{2}$ and desaturation (minimal $\mathrm{SP}, \mathrm{O}_{2}$ - resting $\mathrm{SP}, \mathrm{O}_{2}$ ) were recorded. The resting $\mathrm{HR}$ and peak $\mathrm{HR}$ were evaluated and the chronotropic response was calculated (peak HR - resting HR). Post-walk dyspnoea was recorded using the Borg scale [19]. Haemodynamic evaluation was carried out according to a previous routine protocol [20]. The 6MWT and right heart catheterisation were performed during the same week. In IPAH patients, 40 patients $(87 \%)$ were subsequently treated with either oral bosentan $(n=28)$, intravenous epoprostenol $(n=9)$ or both $(n=3)$. In nonidiopathic PAH patients, 17 patients $(46 \%)$ were subsequently treated with either oral bosentan $(n=10)$, intravenous epoprostenol $(n=5)$ or inhaled iloprost $(n=2)$. A clinical evaluation (NYHA functional class and $6 \mathrm{MWT}$ ) and resting haemodynamics were repeated after $5 \pm 2$ months of treatment.

\section{Statistical analysis}

The IPAH and nonidiopathic PAH groups were analysed separately because IPAH patients form a homogeneous group and are generally free of comorbidities, whereas nonidiopathic $\mathrm{PAH}$ patients suffer from a wide range of associated diseases, potentially influencing their functional status. Results are expressed as mean \pm SD. Univariate regression analysis was performed between the 6-min walking distance (6MWD) and age, height, weight, haemodynamic variables and 6MWT characteristics. In cases where $p<0.20$, the haemodynamic and 6MWT variables under study entered forward stepwise multiple regression analysis. Age, height and weight were also included given the a priori knowledge of their association with the 6MWD [21]. Sex differences were analysed using ANOVA. In the 57 treated patients, the effects of treatment were analysed using repeated-measures ANOVA. A p $<0.05$ was considered statistically significant.

\section{RESULTS}

Clinical characteristics of the patients and resting haemodynamics are shown in table 1.

\section{Correlates of the 6MWD}

Univariate analysis indicated that the walking distance was related to numerous demographic, haemodynamic and walking test characteristics (table 2). In both IPAH and nonidiopathic $\mathrm{PAH}$, the $6 \mathrm{MWD}$ was positively related to cardiac output, stroke volume, mixed venous oxygen saturation and

\section{TABLE 1 Clinical characteristics of the study population at baseline}

Idiopathic PAH Nonidiopathic PAH

\begin{tabular}{|c|c|c|}
\hline Subjects n & 46 & 37 \\
\hline \multicolumn{3}{|l|}{ Demographics } \\
\hline Age yrs & $50 \pm 14$ & $49 \pm 12$ \\
\hline Females/males $\mathrm{n}$ & $27 / 19$ & $11 / 26$ \\
\hline Weight kg & $69 \pm 14$ & $70 \pm 14$ \\
\hline Height $\mathrm{cm}$ & $165 \pm 9$ & $169 \pm 8$ \\
\hline Body surface area $\mathrm{m}^{2}$ & $1.75 \pm 0.19$ & $1.79 \pm 0.18$ \\
\hline \multicolumn{3}{|l|}{ NYHA n } \\
\hline ॥ & 18 & 19 \\
\hline III & 28 & 15 \\
\hline IV & 0 & 3 \\
\hline \multicolumn{3}{|l|}{ Resting haemodynamics } \\
\hline mRAP mmHg & $7 \pm 4$ & $8 \pm 6$ \\
\hline mPAP mmHg & $55 \pm 16$ & $40 \pm 15$ \\
\hline PAOP mmHg & $9 \pm 3$ & $8 \pm 4$ \\
\hline $\mathrm{COL} \cdot \mathrm{min}^{-1}$ & $4.72 \pm 1.11$ & $5.56 \pm 1.64$ \\
\hline $\mathrm{Cl} \mathrm{L} \cdot \mathrm{min}^{-1} \cdot \mathrm{m}^{-2}$ & $2.70 \pm 0.65$ & $3.11 \pm 0.93$ \\
\hline SV mL & $60 \pm 17$ & $70 \pm 24$ \\
\hline $\mathrm{PVR} \mathrm{mmHg} \cdot \min \cdot \mathrm{L}^{-1}$ & $10.6 \pm 4.5$ & $6.8 \pm 4.9$ \\
\hline $\mathrm{Sv}, \mathrm{O}_{2} \%$ & $64 \pm 8$ & $63 \pm 12$ \\
\hline $\mathrm{HR}$ beats $\cdot \mathrm{min}^{-1}$ & $81 \pm 13$ & $81 \pm 14$ \\
\hline mSAP mmHg & $90 \pm 12$ & $88 \pm 13$ \\
\hline \multicolumn{3}{|l|}{ 6MWT } \\
\hline Distance m & $431 \pm 87$ & $423 \pm 104$ \\
\hline $\mathrm{SP}, \mathrm{O}_{2}$,rest \% & $95 \pm 3$ & $95 \pm 3$ \\
\hline $\mathrm{SP}, \mathrm{O}_{2}, \min \%$ & $90 \pm 5$ & $88 \pm 6$ \\
\hline$\Delta S P, O_{2} \%$ & $-5 \pm 4$ & $-8 \pm 5$ \\
\hline HRrest beats $\cdot \mathrm{min}^{-1}$ & $85 \pm 14$ & $89 \pm 16$ \\
\hline HRpeak beats $\cdot \mathrm{min}^{-1}$ & $118 \pm 18$ & $116 \pm 15$ \\
\hline$\Delta \mathrm{HR}$ beats $\cdot \mathrm{min}^{-1}$ & $33 \pm 15$ & $27 \pm 11$ \\
\hline Borg scale & $3.4 \pm 1.6$ & $3.1 \pm 1.3$ \\
\hline
\end{tabular}

Data are presented as mean $\pm \mathrm{SD}$, unless otherwise specified. PAH: pulmonary arterial hypertension; NYHA: modified New York Heart Association; mRAP mean right atrial pressure; mPAP: mean pulmonary arterial pressure; PAOP pulmonary arterial occlusion pressure; $\mathrm{CO}$ : cardiac output; $\mathrm{Cl}$ : cardiac index; SV: stroke volume; PVR: pulmonary vascular resistance; $\mathrm{Sv}, \mathrm{O}_{2}$ : mixed venous oxygen saturation; HR: heart rate; mSAP: mean systemic arterial pressure; 6MWT: 6-min walk test; $S P, \mathrm{O}_{2}$,rest: peripheral oxygen saturation measured at rest; $\mathrm{SP}, \mathrm{O}_{2}$,min: minimal $\mathrm{SP}, \mathrm{O}_{2}$ measured during $6 \mathrm{MWT} ; \Delta \mathrm{SP}, \mathrm{O}_{2}$ : desaturation measured during the $6 \mathrm{MWT}\left(\mathrm{SP}, \mathrm{O}_{2}, \mathrm{~min}-\mathrm{SP}, \mathrm{O}_{2}\right.$,rest); HRrest: heart rate measured at rest; HRpeak: peak heart rate measured during the $6 \mathrm{MWT} ; \Delta \mathrm{HR}$ : chronotropic response (HRpeak-HRrest). $\mathrm{n}=83.1 \mathrm{mmHg}=0.133 \mathrm{kPa}$. 


\begin{tabular}{|c|c|c|c|c|}
\hline \multirow[t]{3}{*}{ TABLE 2} & $\begin{array}{l}\text { hin walking } \\
\mathrm{s} \text {, resting } \\
\text { WT charac } \\
\text { athic and n }\end{array}$ & $\begin{array}{l}\text { listano } \\
\text { emod } \\
\text { ristics } \\
\text { nidiop }\end{array}$ & $\begin{array}{l}\text { nd clinical } \\
\text { mics param } \\
\text { sessed at b } \\
\text { ic PAH }\end{array}$ & $\begin{array}{l}\text { ters } \\
\text { seline }\end{array}$ \\
\hline & \multicolumn{2}{|c|}{ Idiopathic $\mathrm{PAH}^{\#}$} & \multicolumn{2}{|c|}{ Nonidiopathic PAH } \\
\hline & $\begin{array}{r}\text { Regression } \\
\text { coefficient }\end{array}$ & SE & $\begin{array}{c}\text { Regression } \\
\text { coefficient }\end{array}$ & SE \\
\hline \multicolumn{5}{|l|}{ Clinical } \\
\hline Age yrs & $-2.67^{\star \star}$ & 0.84 & -0.95 & 1.47 \\
\hline Height $\mathrm{cm}$ & $4.14^{\star \star}$ & 1.29 & 3.69 & 2.17 \\
\hline Weight kg & -0.82 & 0.93 & -0.42 & 1.25 \\
\hline \multicolumn{5}{|l|}{ Haemodynamics } \\
\hline mRAP $\mathrm{mmHg}$ & -4.32 & 3.04 & $-6.78^{*}$ & 2.88 \\
\hline mPAP mmHg & -0.52 & 0.82 & $-2.58^{*}$ & 1.06 \\
\hline PAOP $\mathrm{mmHg}$ & -7.45 & 4.25 & 2.99 & 4.74 \\
\hline $\mathrm{CO} \mathrm{L} \cdot \mathrm{min}^{-1}$ & $39.15^{\star *}$ & 10.18 & $27.17^{\star \star}$ & 9.68 \\
\hline SV mL & $2.60^{\star \star}$ & 0.65 & $2.85^{\star \star}$ & 0.57 \\
\hline PVR mmHg $\cdot \min \cdot L^{-1}$ & $-5.62^{*}$ & 2.75 & $-9.43^{\star *}$ & 3.22 \\
\hline $\mathrm{Sv}, \mathrm{O}_{2} \%$ & $4.93^{\star \star}$ & 1.69 & $5.20^{\star \star}$ & 1.43 \\
\hline $\mathrm{HR}$ beats $\cdot \mathrm{min}^{-1}$ & -1.23 & 0.99 & $-4.76^{\star \star}$ & 0.97 \\
\hline \multicolumn{5}{|l|}{ 6MWT } \\
\hline $\mathrm{SP}, \mathrm{O}_{2}$, rest \% & 7.77 & 4.02 & $12.24^{\star}$ & 5.02 \\
\hline $\mathrm{SP}, \mathrm{O}_{2}, \min \%$ & -0.27 & 2.71 & $6.53^{*}$ & 2.83 \\
\hline$\Delta S P, \mathrm{O}_{2} \%$ & -4.35 & 2.93 & 4.29 & 3.78 \\
\hline HRrest beats $\cdot \mathrm{min}^{-1}$ & -0.44 & 0.91 & $-3.10^{\star \star}$ & 0.98 \\
\hline HRpeak beats $\cdot \mathrm{min}^{-1}$ & $2.10^{\star *}$ & 0.67 & -0.86 & 1.15 \\
\hline$\Delta \mathrm{HR}$ beats $\cdot \mathrm{min}^{-1}$ & $3.12^{\star *}$ & 0.71 & $4.45^{\star *}$ & 1.34 \\
\hline Borg scale & -15.78 & 8.39 & -18.72 & 13.61 \\
\hline
\end{tabular}

6MWT: 6-min walk test; PAH: pulmonary arterial hypertension; SE: standard error; mRAP: mean right atrial pressure; mPAP: mean pulmonary arterial pressure; PAOP: pulmonary arterial occlusion pressure; $\mathrm{CO}$ : cardiac output; $\mathrm{SV}$ : stroke volume; PVR: pulmonary vascular resistance; $\mathrm{Sv}, \mathrm{O}_{2}$ : mixed venous oxygen saturation; HR: heart rate; $\mathrm{SP}, \mathrm{O}_{2}$,rest: peripheral oxygen saturation measured at rest; $\mathrm{SP}, \mathrm{O}_{2}$, min: minimal $\mathrm{SP}, \mathrm{O}_{2}$ measured during $6 \mathrm{MWT} ; \triangle \mathrm{SP}, \mathrm{O}_{2}$ : desaturation measured during the $6 \mathrm{MWT}\left(\mathrm{SP}, \mathrm{O}_{2}, \mathrm{~min}-\mathrm{SP}, \mathrm{O}_{2}\right.$, rest $)$; HRrest: heart rate measured at rest; HRpeak: peak heart rate measured during the $6 \mathrm{MWT} ; \Delta \mathrm{HR}$ : chronotropic response (HRpeak-HRrest). ${ }^{*}: n=46 ;{ }^{*}: n=37 .{ }^{*}: p<0.05 ;{ }^{* *}: p<0.01$.

chronotropic response; it was negatively related to pulmonary vascular resistance; and was not significantly related to body weight, pulmonary artery occlusion pressure, desaturation and Borg scale. In IPAH, the walking distance was also positively related to body height and peak $\mathrm{HR}$ and was negatively related to age. In nonidiopathic $\mathrm{PAH}$, the walking distance was also positively related to resting and minimal $\mathrm{SP}, \mathrm{O}_{2}$ and negatively related to mean right atrial pressure, mean pulmonary artery pressure and resting HR.

In both IPAH and nonidiopathic PAH patients, stepwise regression analysis indicated that the only factors associated with the 6MWD were stroke volume and chronotropic response (table 3). Individual 6MWD versus stroke volume and chronotropic response relationships are presented in figure 1. Although there was a correlation between resting stroke volume and resting HR measured during catheterisation $(\mathrm{r}=-0.51 ; \mathrm{p}<0.001)$, there was no correlation between resting

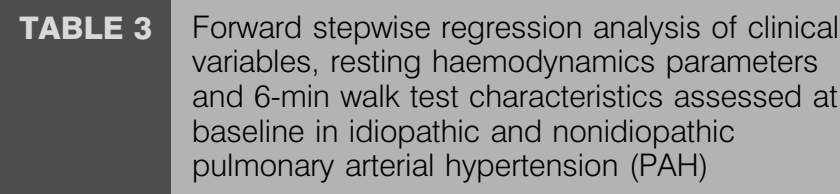

\begin{tabular}{lcccc} 
& $\begin{array}{c}\text { Regression } \\
\text { coefficient }\end{array}$ & SE & p-value & $\begin{array}{c}\mathbf{R}^{2} \text { change } \\
\%\end{array}$ \\
\hline $\begin{array}{l}\text { Idiopathic PAH } \\
\text { (HR }\end{array}$ & 3.62 & 0.50 & $<0.0001$ & 31 \\
$\quad$ SV & 3.07 & 0.44 & $<0.0001$ & 36 \\
$\begin{array}{l}\text { Nonidiopathic PAH } \\
\text { SV }\end{array}$ & 2.46 & 0.47 & $<0.0001$ & 42 \\
$\Delta$ HR $^{*}$ & 3.69 & 0.96 & 0.0005 & 18 \\
\hline
\end{tabular}

$\Delta \mathrm{HR}: \Delta$ heart rate, i.e. chronotropic response (HRpeak-HRrest); SV: stroke volume. Only statistically significant variables are presented. ${ }^{*}: \mathrm{n}=46$, multiple $\mathrm{R}^{2}=0.67 ;{ }^{\bullet} \mathrm{n}=37$, multiple $\mathrm{R}^{2}=0.60$.

stroke volume and the chronotropic response $(\mathrm{r}=-0.14$; $\mathrm{p}=0.339)$.

The influence of sex was also tested. The 6MWD was not significantly different between males and females in both the IPAH group $(459 \pm 92$ versus $412 \pm 79 ; \mathrm{p}=\mathrm{NS})$ and in the nonidiopathic PAH group $(440 \pm 103$ versus $384 \pm 100 ; \mathrm{p}=\mathrm{NS})$. Stroke volume and chronotropic response were the only factors associated with the 6MWD in IPAH females $(n=27$; multiple $\left.\mathrm{R}^{2}=0.58\right)$, IPAH males $\left(\mathrm{n}=19\right.$; multiple $\left.\mathrm{R}^{2}=0.78\right)$ and nonidiopathic PAH males $\left(n=26\right.$; multiple $\left.R^{2}=0.62\right)$. In nonidiopathic $\mathrm{PAH}$ females, stroke volume was the only factor associated with 6MWD $\left(\mathrm{n}=11 ; \mathrm{R}^{2}=0.58\right)$.

\section{Effect of treatment}

The effects of treatment on functional status are presented in table 4 . On average, in both IPAH and nonidiopathic PAH, the 6MWD increased and pulmonary haemodynamics improved following treatment, whereas mean chronotropic response was unchanged (table 5). In IPAH patients $(n=40)$, individual changes in the 6MWD were positively related to changes in cardiac output, stroke volume and chronotropic response (fig. 2a), and negatively related to changes in pulmonary vascular resistance and Borg scale $\left(\mathrm{R}^{2}\right.$ ranging 0.13-15; each $\mathrm{p}<0.05)$. On stepwise regression analysis, changes in the $6 \mathrm{MWD}$ were positively related to changes in stroke volume and in chronotropic response, and negatively related to changes in right atrial pressure (multiple $\mathrm{R}^{2}=0.38 ; \mathrm{p}<0.01$ ). In nonidiopathic PAH $(n=17)$, individual changes in the 6MWD were positively related to changes in chronotropic response (fig. $2 \mathrm{~b}$ ) and negatively related to changes in right atrial pressure $\left(R^{2}=0.23 ; p<0.05\right)$. On stepwise regression analysis, only changes chronotropic response were related to changes in the 6MWD $\left(\mathrm{R}^{2}=0.38 ; \mathrm{p}<0.05\right)$.

\section{DISCUSSION}

The present study indicated that baseline stroke volume and $6 \mathrm{MWT}$ chronotropic response were strongly associated with the $6 \mathrm{MWD}$ in both IPAH and nonidiopathic PAH. The lack of chronotropic response may reflect the loss in normal physiological reserve in more unwell patients. This suggests that 

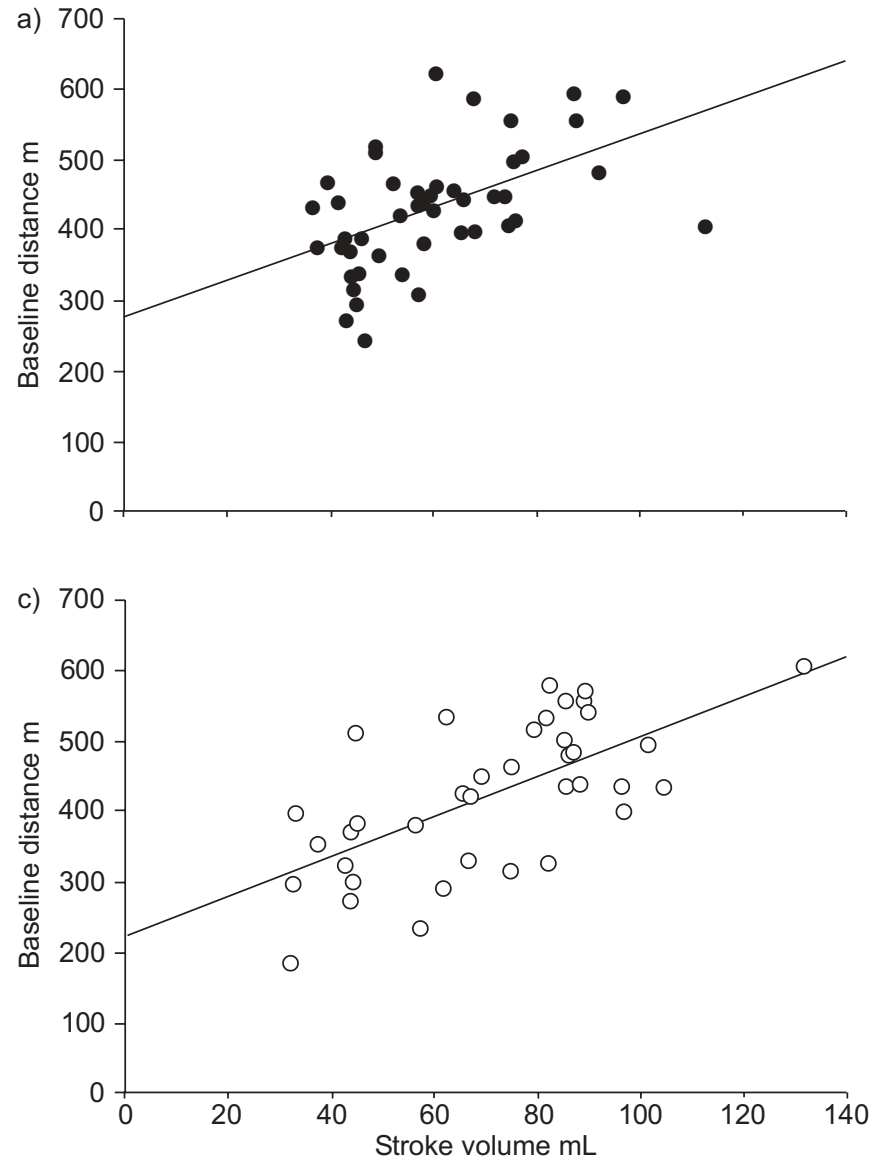

b)

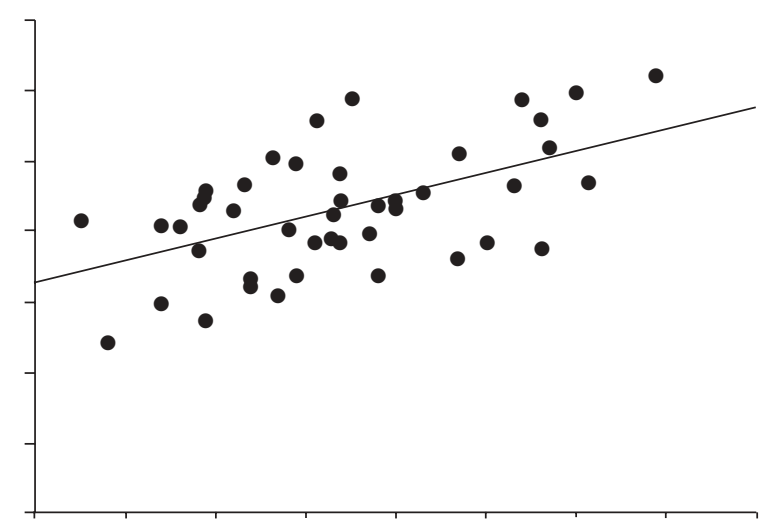

d)

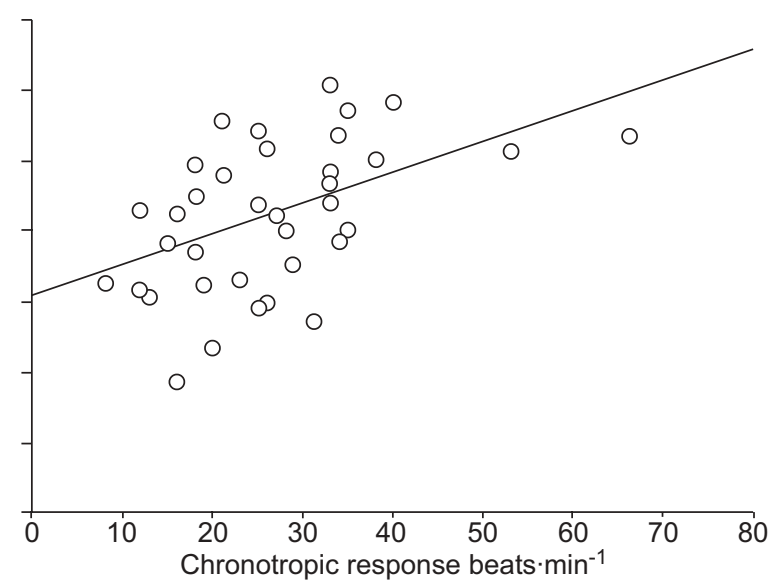

FIGURE 1. Relationship between the 6-min walking distance (6MWD) at baseline and resting stroke volume and chronotropic response (peak heart rate minus resting heart rate measured during the 6-min walk test). In idiopathic pulmonary arterial hypertension patients $(n=46 ; \bullet)$, the only variables related to the baseline $6 \mathrm{MWD}$ in stepwise regression analysis were resting stroke volume $\left(a ; R^{2}=0.27 ; p<0.001\right)$ and chronotropic response $\left(b ; R^{2}=0.31 ; p<0.001\right)$. In nonidiopathic pulmonary arterial hypertension patients $(n=37 ; \bigcirc)$, the only variables related to the baseline 6 -min walking distance in stepwise regression analysis were resting stroke volume $\left(c ; R^{2}=0.42 ; p<0.001\right)$ and chronotropic response $\left(d ; R^{2}=0.24 ; p=0.002\right)$.

\section{TABLE 4}

Effect of treatment on New York Heart Association (NYHA) functional class in idiopathic and nonidiopathic pulmonary arterial hypertension (PAH)

\begin{tabular}{|c|c|c|c|}
\hline \multicolumn{2}{|c|}{ Idiopathic PAH $^{\#}$} & \multicolumn{2}{|c|}{ Nonidiopathic PAH" } \\
\hline Baseline & $\begin{array}{c}\text { Post- } \\
\text { treatment }\end{array}$ & Baseline & $\begin{array}{l}\text { Post- } \\
\text { treatmen }\end{array}$ \\
\hline
\end{tabular}

\begin{tabular}{ccccc}
\hline NYHA n & & & & \\
I & 0 & 1 & 0 & 0 \\
II & 13 & 26 & 3 & 5 \\
III & 27 & 12 & 11 & 12 \\
IV & 0 & 1 & 3 & 0 \\
\hline
\end{tabular}

In idiopathic PAH, treatments included oral bosentan $(n=28)$, intravenous epoprostenol $(n=9)$ and both $(n=3)$. In nonidiopathic PAH, treatments included oral bosentan $(n=10)$, intravenous epoprostenol $(n=5)$ and inhaled iloprost $(n=2){ }^{*}: n=40 ; ": n=17$. chronotropic response must be preserved when managing PAH patients, while the prognostic value of chronotropic response deserves further studies.

In the current study, in the IPAH group, the median distance walked in 6 min was higher than that reported by МіҮАмото et al. [5] (432 versus $332 \mathrm{~m}$ ), and this may be explained by differences in patients' characteristics, mainly body surface area and functional status. In pulmonary hypertensive patients, two preliminary reports have recently demonstrated that the peak oxygen uptake $\left(V^{\prime} \mathrm{O}_{2}\right)$ reaches $60 \%$ of the maximal predicted value during $6 \mathrm{MWT}$, and generates high metabolic response, with $V^{\prime} \mathrm{O}_{2}$ very close to the peak $V^{\prime} \mathrm{O}_{2}$ observed during cardiopulmonary exercise testing $[22,23]$. The current data are consistent with previous observations that pretreatment walking distance is related to indices of right heart function [5], and that there is a positive relationship between increases in right ventricular stroke volume and improved 6MWD in IPAH treated with epoprostenol [24].

During submaximal exercise, pulmonary hypertensive patients display a limited increase in stroke volume [9-11], and this 


\begin{tabular}{|c|c|c|c|c|c|}
\hline \multirow[t]{3}{*}{ TABLE 5} & \multicolumn{5}{|c|}{$\begin{array}{l}\text { Changes in functional class, haemodynamics } \\
\text { and six-minute walk test (6MWT) characteristics } \\
\text { observed after } 5 \pm 2 \text { months of treatment in } \\
\text { idiopathic and nonidiopathic pulmonary arterial } \\
\text { hypertension (PAH) }\end{array}$} \\
\hline & & \multicolumn{2}{|c|}{ Idiopathic $\mathrm{PAH}^{\#}$} & \multicolumn{2}{|c|}{ Nonidiopathic PAH } \\
\hline & & Baseline & $\begin{array}{l}\text { Post- } \\
\text { treatment }\end{array}$ & Baseline & $\begin{array}{c}\text { Post- } \\
\text { treatment }\end{array}$ \\
\hline \multicolumn{6}{|c|}{ Haemodynamics } \\
\hline $\mathrm{mRAP} \mathrm{mmH}$ & & $7 \pm 4$ & $8 \pm 5$ & $10 \pm 7$ & $7 \pm 4^{\star \star}$ \\
\hline $\mathrm{mPAP} \mathrm{mmH}$ & & $58 \pm 13$ & $52 \pm 15^{\star *}$ & $49 \pm 13$ & $45 \pm 9$ \\
\hline PAOP $\mathrm{mmH}$ & & $9 \pm 3$ & $8 \pm 3$ & $8 \pm 4$ & $7 \pm 3$ \\
\hline $\mathrm{CO} L \cdot \mathrm{min}^{-1}$ & & $4.69 \pm 1.16$ & $5.23 \pm 1.23^{* *}$ & $4.76 \pm 1.58$ & $5.66 \pm 1.65^{\star \star}$ \\
\hline SV mL & & $59 \pm 18$ & $67 \pm 21^{* *}$ & $57 \pm 23$ & $65 \pm 21^{* *}$ \\
\hline PVR mmHg & $\min \cdot L^{-1}$ & $11.3 \pm 4.0$ & $9.1 \pm 4.1^{\star \star}$ & $10.0 \pm 5.2$ & $7.3 \pm 3.1^{* *}$ \\
\hline $\mathrm{Sv}_{\mathrm{O}} \mathrm{O}_{2} \%$ & & $64 \pm 8$ & $65 \pm 8$ & $60 \pm 13$ & $64 \pm 9$ \\
\hline HR beats $\cdot \mathrm{m}$ & & $81 \pm 12$ & $80 \pm 12$ & $86 \pm 14$ & $88 \pm 11$ \\
\hline \multicolumn{6}{|c|}{ 6MWT characteristics } \\
\hline Distance & & $429 \pm 92$ & $456 \pm 105^{*}$ & $375 \pm 92$ & $420 \pm 76^{\star \star}$ \\
\hline SP, $\mathrm{O}_{2}$, rest \% & & $95 \pm 3$ & $96 \pm 2$ & $94 \pm 3$ & $94 \pm 4$ \\
\hline $\mathrm{SP}, \mathrm{O}_{2}, \min \%$ & & $90 \pm 5$ & $92 \pm 4^{* *}$ & $87 \pm 6$ & $88 \pm 7$ \\
\hline$\Delta S P, \mathrm{O}_{2} \%$ & & $-5 \pm 4$ & $-3 \pm 3^{*}$ & $-8 \pm 4$ & $-7 \pm 4$ \\
\hline HRrest beats & $\min ^{-1}$ & $86 \pm 15$ & $83 \pm 11$ & $92 \pm 14$ & $93 \pm 9$ \\
\hline HRpeak beat & $\mathrm{s} \cdot \mathrm{min}^{-1}$ & $120 \pm 18$ & $120 \pm 16$ & $121 \pm 15$ & $120 \pm 9$ \\
\hline$\Delta \mathrm{HR}$ beats $\cdot 1$ & & $34 \pm 16$ & $37 \pm 17$ & $29 \pm 14$ & $27 \pm 9$ \\
\hline Borg scale & & $3.5 \pm 1.7$ & $2.6 \pm 1.6^{\star \star}$ & $3.6 \pm 1.2$ & $2.5 \pm 1.1^{* *}$ \\
\hline
\end{tabular}

Data are expressed as mean \pm SD. Only statistically significant relationships are noted. In idiopathic $\mathrm{PAH}$, treatments included oral bosentan $(\mathrm{n}=28)$, intravenous epoprostenol $(n=9)$ and both $(n=3)$. In nonidiopathic PAH, treatments included oral bosentan $(n=10)$, intravenous epoprostenol $(n=5)$ and inhaled iloprost $(n=2)$. mRAP: mean right atrial pressure; mPAP: mean pulmonary arterial pressure; PAOP: pulmonary arterial occlusion pressure; $\mathrm{CO}$ : cardiac output; SV: stroke volume; PVR: pulmonary vascular resistance; $\mathrm{Sv}_{1} \mathrm{O}_{2}$ : mixed venous oxygen saturation; HR: heart rate; $\mathrm{SP}, \mathrm{O}_{2}$,est: peripheral oxygen saturation measured at rest; $\mathrm{SP}, \mathrm{O}_{2}$, min: minimal $\mathrm{SP}, \mathrm{O}_{2}$ measured during $6 \mathrm{MWT}$; $\triangle S P, \mathrm{O}_{2}$ : desaturation measured during the $6 \mathrm{MWT}\left(\mathrm{SP}, \mathrm{O}_{2}, \mathrm{~min}-\mathrm{SP}, \mathrm{O}_{2}\right.$, rest); HRrest: heart rate measured at rest; HRpeak: peak heart rate measured during the 6MWT; $\triangle \mathrm{HR}$ : chronotropic response (HRpeak-HRrest). ${ }^{\#}: \mathrm{n}=40 ;{ }^{\bullet}: \mathrm{n}=17$. * $p<0.05 ; * \star: p<0.01$.

may be explained by several mechanisms: decreased right ventricular pre-load reserve; decreased right ventricular inotropic reserve; afterload mismatch; myocardial ischaemia; major tricuspid insufficiency; impaired right-left ventricular interaction; and right ventricular diastolic function $[9,10,16]$. It may be hypothesised that the HR increases during 6MWT either reflect the inability to increase stroke volume (and, thus, the severity of the disease) or may be the only mechanism available to increase cardiac output. The present study demonstrated that both baseline stroke volume and exercise chronotropic response played a contributory role in exercise capacity in both IPAH and nonidiopathic PAH patients, and this ruled out the hypothesis that the increases in HR reflect the severity of the disease. Consistent results were obtained in the overall population of treated patients $(n=57)$, with increases in walking distance being related to increases in
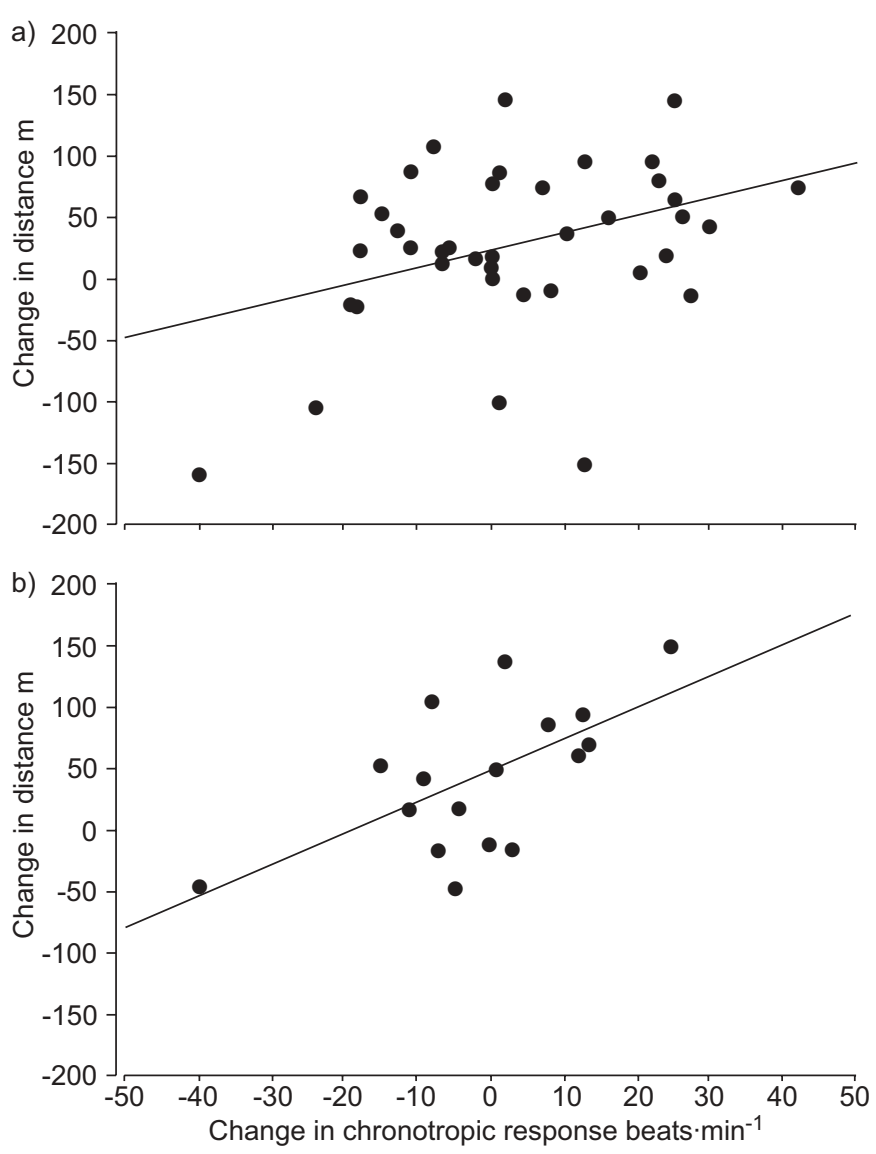

FIGURE 2. Relationship between treatment-induced changes in the 6-min walking distance (6MWD) and treatment-induced changes in the chronotropic response in idiopathic pulmonary arterial hypertension patients (IPAH; $a ; n=40$; $\left.R^{2}=0.14 ; p=0.018\right)$ and nonidiopathic pulmonary arterial hypertension (PAH) patients $\left(b ; n=17 ; R^{2}=0.38 ; p<0.001\right)$. In $I P A H$, changes in distance were also related to changes in stroke volume and right atrial pressure in stepwise regression analysis (multiple $\mathrm{R}^{2}=0.38, \mathrm{p}<0.01$ ). In nonidiopathic $\mathrm{PAH}$, the change in chronotropic response was the only variable related to change in $6 \mathrm{MWD}$ in stepwise regression analysis.

chronotropic response. It must be noted, however, that individual responses were heterogeneous (fig. 2).

During exercise in healthy subjects, the positive chronotropic effect is mediated through vagal withdrawal and increased sympathetic stimulation at the sinus node level. The $\beta$ adrenoreceptor stimulation leads to intracellular adenylate cyclase activation resulting in increased cyclic adenosine monophosphate level. The chronotropic incompetence may be partly explained by decreased activity of the catalytic subunit of adenylate cyclase, as documented in right ventricle from pulmonary hypertensive patients [25]. A previous study has suggested that myocardial $\beta$-adrenergic receptor downregulation is partially responsible for the reduced chronotropic responses to peak exercise in patients with mild-to-moderate symptomatic heart failure due to idiopathic dilated cardiomyopathy [26]. Finally, reduced chronotropic response may be a secondary phenomenon reflecting chronic illness deconditioning. These abnormalities may contribute to explain 
the decreased chronotropic response previously documented in $\mathrm{PAH}$ patients during maximal exercise [12-14].

One potential clinical implication of the current study is to raise caution on the use of drugs limiting HR increases on exercise (e.g. $\beta$-blocking agent), which could be harmful in such patients. Furthermore, various treatments are currently used in $\mathrm{PAH}$, and further studies are needed to investigate the contribution of improved chronotropic response in explaining potential differences in the benefits of these new PAH treatments. Finally, the new information provided by the present study is essentially pathophysiological, and the current authors did not aim to recommend the monitoring of HR response in the routine evaluation of PAH patients. It remains to be documented whether the evaluation of PAH patients' prognosis could be improved by taking into account HR responses during exercise.

The first limitation of the current study was that the study design did not allow the establishment of a cause and effect relationship between HR response and 6MWD. One possibility could be that better cardiopulmonary performance for whatever reason may allow a subgroup of $\mathrm{PAH}$ patients to walk more, thus soliciting, per se, a higher HR. In other words, what the current study may be observing is that patients are variably walking less far and, thus, not utilising their HR reserve, rather than an intrinsic inability to raise HR limiting their exercise capacity. For obvious ethical reasons and given the severity of the disease, it was not possible to solve this problem by studying the effects of cardiac pacing or chronotropic pharmacological changes on the 6MWD-chronotropic response relationship. Physical fitness, which was not quantified in the current study, may also have influenced the response of $\mathrm{HR}$ to exercise. However, the main hypothesis is supported by the fact that, in patients with portopulmonary hypertension, the withdrawal of $\beta$-blockers (given for prophylaxis of variceal bleeding) leads to sustained improvement in $6 \mathrm{MWD}$ in close relationship to increases in chronotropic response [27]. The second limitation was that the current results essentially apply to NYHA functional class II and III patients. Whether or not these results also apply to patients with resting hypoxaemia or congenital heart defect remains unknown. However, taking these limitations into account, it must be noted that this is the first study to document a relationship between HR responses and 6MWD in PAH, and that the data were prospectively obtained in one of the largest series of 6MWT in PAH.

In conclusion, baseline stroke volume and 6-min walk test chronotropic response were strongly associated with the 6-min walking distance in both idiopathic pulmonary arterial hypertension and nonidiopathic pulmonary arterial hypertension. Considering that the 6-min walking distance currently provides benchmarks for disease severity, response to therapy and progression, the current results help to clarify the factors associated with preserved functional status in pulmonary arterial hypertension patients.

\section{ACKNOWLEDGEMENTS}

The authors would like to thank M. Bac, P. Bronne, S. Lenoir and E. Tricard for excellent technical assistance.

\section{REFERENCES}

1 McGoon M, Gutterman D, Steen V, et al. Screening, early detection, and diagnosis of pulmonary arterial hypertension: ACCP evidence-based clinical practice guidelines. Chest 2004; 126: Suppl. 1, 14S-34S.

2 Galie N, Torbicki A, Barst R, et al. Guidelines on diagnosis and treatment of pulmonary arterial hypertension. The Task Force on Diagnosis and Treatment of Pulmonary Arterial Hypertension of the European Society of Cardiology. Eur Heart J 2004; 25: 2243-2278.

3 Barst RJ, McGoon M, Torbicki A, et al. Diagnosis and differential assessment of pulmonary arterial hypertension. J Am Coll Cardiol 2004; 43: Suppl. 12, 40S-47S.

4 Humbert M, Sitbon O, Simonneau G. Treatment of pulmonary arterial hypertension. N Engl J Med 2004; 351: 1425-1436.

5 Miyamoto S, Nagaya N, Satoh T, et al. Clinical correlates and prognostic significance of six-minute walk test in patients with primary pulmonary hypertension. Comparison with cardiopulmonary exercise testing. Am J Respir Crit Care Med 2000; 161: 487-492.

6 ATS Committee on Proficiency Standards for Clinical Pulmonary Function Laboratories. ATS statement: guidelines for the six-minute walk test. Am J Respir Crit Care Med 2002; 161: 111-117.

7 Paciocco G, Martinez FJ, Bossone E, Pielsticker E, Gillespie B, Rubenfire M. Oxygen desaturation on the six-minute walk test and mortality in untreated primary pulmonary hypertension. Eur Respir J 2001; 17: 647-652.

8 Peacock A, Naeije R, Galie N, Reeves JT. End points in pulmonary arterial hypertension: the way forward. Eur Respir J 2004; 23: 947-953.

9 Laskey WK, Ferrari VA, Palevsky HI, Kussmaul WG. Pulmonary artery hemodynamics in primary pulmonary hypertension. J Am Coll Cardiol 1993; 21: 406-412.

10 Nootens M, Wolfkiel CJ, Chomka EV, Rich S. Understanding right and left ventricular systolic function and interactions at rest and with exercise in primary pulmonary hypertension. Am J Cardiol 1995; 75: 374-377.

11 D'Alonzo GE, Gianotti L, Dantzker DR. Noninvasive assessment of hemodynamic improvement during chronic vasodilator therapy in obliterative pulmonary hypertension. Am Rev Respir Dis 1986; 133: 380-384.

12 Deboeck G, Niset G, Lamotte M, Vachiery JL, Naeije R. Exercise testing in pulmonary arterial hypertension and in chronic heart failure. Eur Respir J 2004; 23: 747-751.

13 Riley MS, Porszasz J, Engelen MP, Brundage $\mathrm{BH}$, Wasserman K. Gas exchange responses to continuous incremental cycle ergometry exercise in primary pulmonary hypertension in humans. Eur J Appl Physiol 2000; 83: 63-70.

14 Sun XG, Hansen JE, Oudiz RJ, Wasserman K. Exercise pathophysiology in patients with primary pulmonary hypertension. Circulation 2001; 104: 429-435.

15 Wasserman K, Hansen J, Sue D, Casaburi R, Whipp B. Relationship of $\mathrm{VO}_{2}$ and heart rate: the maximum oxygen pulse. In: Wasserman K, Hansen J, Sue D, Casaburi R, Whipp B, eds. Principles of exercise testing and interpretation. 3rd Edn. Baltimore, Lippincott Williams \& Williams, 1999; pp. 143-164. 
16 Chemla D, Castelain V, Hervé P, Lecarpentier Y, Brimioulle S. Haemodynamic evaluation of pulmonary hypertension. Eur Respir J 2002; 20: 1314-1331.

17 Simonneau G, Galie N, Rubin LJ, et al. Clinical classification of pulmonary hypertension. J Am Coll Cardiol 2004; 43: Suppl. 12, 5S-12S.

18 Humbert M, Barst RJ, Robbins IM, et al. Combination of bosentan with epoprostenol in pulmonary arterial hypertension: BREATHE-2. Eur Respir J 2004; 24: 353-359.

19 Borg GA. Psychophysical bases of perceived exertion. Med Sci Sports Exerc 1982; 14: 377-381.

20 Sitbon O, Brenot F, Denjean A, et al. Inhaled nitric oxide as a screening vasodilator agent in primary pulmonary hypertension. A dose-response study and comparison with prostacyclin. Am J Respir Crit Care Med 1995; 151: 384-389.

21 Enright PL, Sherrill DL. Reference equations for the sixminute walk in healthy adults. Am J Respir Crit Care Med 1998; 158: 1384-1387.

22 Celis D, Vilaro J, Valera J, et al. Physiological responses to the $6 \mathrm{~min}$ walk test in patients with pulmonary arterial hypertension. Am J Respir Crit Care Med 2004; 169: A172.

23 Probst S, Troosters T, Coosemans I, et al. 6MWD in patients with pulmonary arterial hypertension (PAH). Eur Respir J 2003; 22: 464S.

24 Roeleveld RJ, Vonk-Noordegraaf A, Marcus JT, et al. Effects of epoprostenol on right ventricular hypertrophy and dilatation in pulmonary hypertension. Chest 2004; 125 : 572-579.

25 Bristow MR, Minobe W, Rasmussen R, et al. Betaadrenergic neuroeffector abnormalities in the failing human heart are produced by local rather than systemic mechanisms. J Clin Invest 1992; 89: 803-815.

26 White M, Yanowitz F, Gilbert EM, et al. Role of betaadrenergic receptor downregulation in the peak exercise response in patients with heart failure due to idiopathic dilated cardiomyopathy. Am J Cardiol 1995; 76: 1271-1276.

27 Provencher S, Hervé P, Jais Y, et al. Deleterious effects of beta-blockers on exercise capacity and hemodynamics in patients with portopulmonary hypertension. Gastroenterology 2006; In press. 